\title{
Forecasting the Probability of Recessions in South Africa: The Role of Decomposed Term-Spread and Economic Policy Uncertainty
}

\author{
Goodness C. Aye*, Christina Christou**, Luis A. Gil-Alana ${ }^{* * *}$ and Rangan Gupta ${ }^{* * * *}$
}

\begin{abstract}
This paper decomposes the term spread into the expectation and the term premium components using a fractional integration approach and subsequently uses same with the economic policy uncertainty index to forecast the probability of recession in South Africa. We use different specifications of the probit model and quarterly data from 1990:1 to 2012:1. Our out-of-sample results show that the model that incorporates the expectation component and economic policy uncertainty provides the best forecast of recession. All three recession periods in our sample were accurately dictated by the prediction models and the best forecast occurred at the four quarters ahead horizon. A robustness check with a longer sample from 1946q1 to 2017q4 but excluding the factors and economic policy uncertainty due to data limitation, provided justification for decomposing the term spread as the model with the expected spread turned out to be the best. We draw the implications of these findings.
\end{abstract}

Keywords: Expected term spread; term premium; economic policy uncertainty; recession; outof-sample forecast; Probit model.

JEL Classification: C25, E37, E44, E52, E62.

\section{Introduction}

The timely and accurate forecasting of business cycle turning points is one of the key policyrelevant aspects of macroeconomic forecasting. Although, this exercise has been ongoing, the recent financial crisis and the global economic recession of 2007-2009 have heightened interest in predicting business cycles. This paper is aimed at predicting South Africa's recession using aggregate and decomposed term spread (yield curve) as well as an economic policy uncertainty index. The term economic recession is better understood from the concept of the business cycle which has to do with expansions and contractions representing upward and downward swings respectively with respect to aggregate economic activity (Moore, 1967). The National Bureau of Economic Research (NBER) defines the period from a peak to a trough as a recession, while an expansion is the period extending from a trough to a peak (Pauwels and Vasnev, 2014). NBER officially dates the beginning and end of the US recessions and it defines recession as "a significant decline in activity spread across the economy, lasting more than a few months, visible in industrial production, employment, real income, and wholesale-retail trade" (NBER, 2001:1). However, it is noted that the list of economic variables to be used as indicators of decline or growth is not limited to the four in the definition. Alternatively, an economy is said to have

${ }^{*}$ Corresponding author Department of Economics, University of Pretoria, Pretoria, 0002, South Africa. Email: goodness.aye@gmail.com.

${ }^{* *}$ School of Economics and Management, Open University of Cyprus, 2252, Latsia, Cyprus. Email: christina.christou@ouc.ac.cy.

*** Universidad de Navarra, Faculty of Economics and Business Administration, Edificio Biblioteca, Entrada Este E31080, Pamplona, Spain. Email: alana@unav.es.

****Department of Economics, University of Pretoria, Pretoria, 0002, South Africa. Email: rangan.gupta@up.ac.za. 
undergone a recession if economic growth is negative for two or more consecutive quarters (Karunaratne, 2002; Moneta, 2005).

Although recessions are relatively rare events, they occur with potentially strong negative consequences for individuals as well as businesses. This may lead to loss of funds by private and financial institutions arising from a shortage of investment flows, consequently leading to downsizing of the work force and increasing unemployment in the economy. As unemployment increases, this may further lead to loss of tax revenue and hence budget deficits as the government tries to resuscitate the economy. Since recession affects every segment of the economy, Central bankers, investors, policy makers, private forecasters and business professionals are generally interested in knowing which indicators provide reliable, accurate, and potential forecasts of recession.

One of the indicators most widely relied on for forecasting future economic activity and the probability of a recession, has been the yield spread between long- and short-term interest rates (Hamilton and Kim, 2002; Estrella et al., 2003; Chauvet and Potter, 2005). Kessel (1965) was the first to focus specifically on the behaviour of the term spread across the business cycle. When downward sloping, the yield curve has been found to be consistent with a heightened probability of a period of negative or sharply lower real economic growth (Erdogan et al., 2015).However, there is some evidence that the yield curve's predictive ability is deteriorating (Dombrosky and Haubrich, 1996; Estrella and Mishkin, 1997; Khomo and Aziakpono, 2007; Chinn and Kucko, 2015). The weak performance of the term spread may arise from the fact that it may be compromising some predictive content arising from its subcomponents: the expected short spread or term premium (Rosenberg and Maurer, 2008; Gupta et al., 2015). Therefore, of particular interest to the current study is the fact that the yield spread is determined by the financial market's expectation of future short rates and a term premium and hence can be decomposed into separate contributions of expected changes in short interest rates and the term premium.

Hamilton and Kim (2002) noted that the expectation effect or the term premium effect could provide explanations to the relationship between the yield spread and future economic activity and hence recession. The two scenarios are explained in detail in Hamilton and Kim (2002); we provide a brief discussion here. On the one hand, assume the monetary authority decides to adopt a contractionary monetary policy, which will cause market participants to expect a temporary rise in short-term interest rates. According to the expectations hypothesis, the longterm rate should rise less than the short-term rate in the case that the current short-term interest is higher than the expected future short-term rate. This will lead to the flattening of the yield spread and consequently a reduction in spending in interest sensitive sectors of the economy, and hence slow economic growth.

On the other hand, an expansionary monetary policy would lead to a high yield spread, which would signal faster future real economic growth. If market agents anticipate an economic boom and future higher rates of return to investment, according to the expectations hypothesis, the expected future short rates will exceed the current short rate, leading to the yield on long-term bonds to rise more than the short-term yields. These two interpretations on the predictive ability of the yield spread for future economic growth and hence recessions are hinged on its role as a signal of future expected short rates. However, the spread also comprises of a term premium, which compensates investors for the risks associated with holding long-term rather than shortterm investments. For instance, if interest rates become more volatile at the end of an expansion, this could reduce the spread. Hence long rates may fall relative to short rates at the end of an expansion, because the cyclical volatility warrants a change in the risk premium and not necessarily because future short rates are expected to fall (Hamilton and Kim, 2002). 
Ergungor (2016) noted that the reliability of the term spread as a predictor may have been affected by short-term interest rates being very close to zero. Long-term yields cannot be negative, due to the portfolio constraints of institutional investors. Therefore, the yield curve may not invert when it should or as much as it should despite the anticipated path of the economy. On this basis, we also augment our analysis with the economic policy uncertainty (EPU) index following Karnizova and Li (2014). The argument that uncertainty about taxes, government spending and other policy matters deepened the recession of 2007-2009 and slowed the recovery, lead to the construction of the first news-based economic policy uncertainty index by Baker et al. (2016). Theoretically, economic policy uncertainty can forewarn recessions. For instance, increased uncertainty about fiscal policy can cause a delay in investment and hiring decisions, consequently triggering a prolonged downturn. When the policy uncertainty is resolved, the downturn is likely to be followed by an economic recovery (Born and Pfeifer, 2014; Fernández-Villaverde et al., 2015).

Given the above background, we contribute to the literature by forecasting the probability of recession in South Africa using the expectations and term premium components of the term spread similar to Ang et al. (2006) and Gupta et al., (2015) who used the unobserved subcomponents of the term spread to predict real GDP growth. We decompose the term spread using the fractional integration approach of Gil-Alana and Moreno (2012) as this introduces a route to avoid the specification error present in many models of the term structure of interest rates. We also augment the probit forecasting models with the economic policy uncertainty index. We are not aware of any studies that examined the forecasting ability of the subcomponents of the term spread and economic policy uncertainty together for recession probability. Further, all our probit models incorporate information from other macroeconomic fundamentals based on five extracted factors. We perform both in-sample and out-of-sample forecasting analyses of recession unlike previous related studies in South Africa which performed mostly in-sample analyses. This is based on Estrella and Mishkin (1996), who pointed out that the out-of sample forecast provides a truer forecasting ability of an indicator since the out-ofsample predictions account for forecasts in periods beyond which the models are estimated for.

The rest of the paper is structured as follows; the literature review is presented in Section 2; Section 3 presents the data and empirical model of economic recession; results are presented in Section 4 while Section 5 provides the conclusion.

\section{Literature Review}

We provide an overview of empirical studies on forecasting economic recessions. For instance, Estrella and Mishkin (1998) investigate the out-of-sample performance of various financial (interest rates and spreads, stock prices, and monetary aggregates) and non-financial variables as predictors of U.S. recessions. Results based on the probit model show that stock prices are useful with one- to three-quarter horizons, as are some well-known macroeconomic indicators. However, beyond one quarter, the slope of the yield curve performed better than other variables. Galvaõ (2006) used a structural break threshold VAR model and confirms that spread as the leading indicator of the U.S. recessions, concluding that it is able to correctly anticipate the timing of the 2001 recession.

Rosenberg and Maurer (2008) investigate whether changes in the term premium tend to distort the term spread's recession signals. Using a decomposition approach based on Kim and Wright (2005) and a probit model, they find that the expectations component is indeed a leading indicator of recession in US, while the term premium component is not. They also find that a model based on the expectations component predicts recession more accurately than that based on the term spread. Our study differs from this by including the economic policy uncertainty 
index as well as information from a large set of macroeconomic fundamentals. Moreover, we use a more flexible approach (fractional integration) in decomposing the term spread. With a dynamic probit model that incorporates various risk factors such as financial market expectations, credit or liquidity risks in the general economy, the risks of negative wealth effects resulting from the bursting of asset price bubbles, and signs of deteriorating macroeconomic fundamentals, $\mathrm{Ng}$ (2012) shows that the dynamic probit models outperform the static model in terms of predicting the duration of recessions in the US. However, the static probit model with the risk factors is as good as the dynamic probit models with respect to forecasting the peaks of business cycles.

Ratcliff (2013) evaluates probabilistic and non-probabilistic forecasts from probit models that use the slope of the yield curve to forecast recessions in the US. The findings show that these models give reliable non-probabilistic warnings of recessions, but the estimated probabilities do not match the conditional frequency of recession months. Pauwels and Vasnev (2014) evaluate one-step ahead out-of-sample forecast of the US recession using log-score and quadratic-score based weights. They find that the forecast accuracy improves when combining the probability forecasts of both the coincident indicators model and the yield curve model, compared to each model's own forecasting performance.

To predict US recessions, Karnizova and Li (2014) employ probit models which incorporate economic policy uncertainty indexes alongside financial variables such as aggregate yield spreads, stock returns and stock market volatility. They find that the policy uncertainty indexes are statistically and economically significant in forecasting recessions at the horizons beyond five quarters. Also the policy index based outperformed the term spread at the longer horizons. We extend this study by using both the aggregate and decomposed yield spread as well as extracted factors from macroeconomic fundamentals. Erdogan et al. (2015) employ the probit model and provide in-sample and out-of-sample evidence of the improvement in forecasting US recession by combining the yield curve with the stock market depth and liquidity deviation factor.

Employing a Markov switching model and a nonlinear multivariate dynamic factor model, Chauvet and Senyuz (2016) show that including information extracted from the level and curvature of the yield curve with the standard slope provided substantial incremental predictive value for the phases of the US business cycle. Chatterjee (2016) investigates three distinct aspects of stock market trading activities, namely stock market liquidity, returns and volatility as predictors of U.S. recessions. Results based on probit models show that stock market liquidity and forecasts recessions up to three and two quarters ahead respectively, while stock market volatility has no forecasting power. Also Chatterjee et al. (2018) examined the relationship between bank liquidity creation and recessions in the U.S using probit model. The findings show that lower bank on-balance sheet liquidity creation predicts recessions four quarters into the future while off-balance sheet liquidity creation does not predict recessions well at longer forecast horizons. Moreover, liquidity creation of larger banks predicts recessions better relative smaller banks. Guérin and Leiva-Leon (2017) using dynamic model averaging with Markovswitching models forecast U.S. recessions with state-level employment data. They show that for a specifically, the index from the Survey of Professional Forecasters.

Using a dynamic probit model Nyberg (2010) shows that the domestic term spread, stock market returns and the foreign term spread have predictive power in the US and Germany while the interest rate differential between the US and Germany is also a useful additional predictor of recessions in Germany. Their model was able to provide accurate out-of-sample forecasts for the 2001 and 2008 recessions in both countries. Also Nyberg (2014) uses a binary bivariate autoregressive probit model that allows for links between the recession probabilities in the US and Germany. They provide evidence of in-sample and out-of-sample predictability of recession 
periods by the US and German term spreads and stock market returns. In another study for the US and Germany, Proaño and Theobald (2014) developed a composite indicator for real-time recession forecasting based on alternative dynamic probit models. Results from the combined recession probability forecasts show both in-sample and out-of-sample ability for the two economies. Döpke e at. (2017) using Germany data and boosted regression trees found that measures of the short-term interest rate and the term spread are important leading indicators of recession and that while the importance of the former has declined over the years, the term spread and the stock market have gained in importance.

Moneta (2005) examines the predictive power of ten variations of the yield spreads for different segments of the yield curve for recessions in the Euro area using the probit model. The yield spread between the ten-year government bond rate and the three-month interbank rate outperforms all other spreads in predicting recessions in the euro area both in-sample and outof-sample. Yet for the Euro area, Duarte et al. (2005) applied both linear and nonlinear regression models and confirm the ability of the yield curve as a leading indicator for economic growth. Also their findings show that probit models that use the EMU and the US yield spreads are successful in predicting EMU recessions. Chionis et al. (2010) use quarterly data from 1994:1 to 2008:3 to predict recession in the European Union (EU15). Augmenting the standard yield curve with unemployment and a composite European stock price index, they find that this has significant forecasting power for EU15.

For the Japanese economy, Hasegawa and Fukuta (2011) use a probit model that accounted for structural breaks to compare predictive ability of the yield spread, stock returns and money supply. They find that whereas the Japanese yield spread contains more precise information on future recessions than stock returns and nominal money supply before the structural break, the yield spread cannot predict future recessions after the break. Money supply had no predictive power for the entire sample period.

Moersch and Pohl (2011) use two different definitions of recessions, and examine the ability of the term spread to predict recessions for seven countries namely Australia, Canada, France, Germany, Japan, the United Kingdom and the United States. Probit model results show that the predictive power of the term spread is best for Canada, Germany, the United States and the United Kingdom. Furthermore, the predictive power of the spread is due to factors other than the stance of monetary policy alone.

With respect to South Africa, there are limited studies on recession prediction. For instance, Moolman (2002) uses a probit model and quarterly data for the period 1979:1 to 2001:3 to perform an in-sample prediction of the probability of recession in South Africa with the slope of the yield curve. The results show that the probability of a recession in a specific quarter is a negative function of the yield spread lagged two quarters and the yield curve successfully predicts turning points of the business cycle two quarters ahead.

Khomo and Aziakpono (2007) evaluate the in-sample predictive ability of the yield curve for recessions in South Africa against other variables such as the growth rate of real money supply, changes in stock prices and the index of leading economic indicators. Results based on the standard probit model and data from January 1980 to June 2004 show that real M3 growth lacks predictive power for future recessions, whilst the All-Share index provides information for up to 12 months though not better than the yield curve. In the short-run up to 4 months the index of leading economic indicators outperforms the yield spread whereas the latter performs better at longer horizons. They also indicated that the yield curve predicted most of South Africa's recessions since 1980 , but an incorrect probability of about $84 \%$ of South Africa being in recession in April and May 2003. 
Clay and Keeton (2011) use both static and dynamic probit models to examine the yield curve's in-sample forecasting abilities for economic downturns in South Africa. They confirm Khomo and Aziakpono's finding that the yield curve falsely predicted a downswing in 2002/03. However, they also find that the yield curve has not lost its predictive power in the most recent downturn of 2007/09 and has been able to provide a better forecast since 1980 than the JSE All Share Index, the SA Reserve Bank's leading economic indicator and M3 money supply with the best forecast at two quarters ahead.

Mohapi and Botha (2013) examine the predictive ability of the South African term spread, and those of China, United States (U.S.) and Germany for South Africa's recessions. Results based on a dynamic probit model and quarterly data from 1980:1 to 2012:2 show that the South African term spread accurately predicted all the South Africa's recessions since 1980; the 1996 and 2008 recessions were accurately predicted by the Chinese term spread. Some recessions were predicted by the U.S. term spread while German term spread predictions were counter-cyclical. In an attempt to explain the 2002/03 false prediction of the yield spread, Botha and Keeton (2014) find that aside from 2002/03, the yield spread has successfully predicted all previous downswings in the South African economy with the best prediction at five months ahead. From the South African studies, it seems the best forecasting horizon is shorter (2 quarters) than that obtained by most studies especially in the US and Europe where the yield curve gives its best results in a forecasting horizon of four to eight quarters. Also aside from Mohapi and Botha (2013), these studies focused on in-sample forecasting.

From the foregoing, we observe that although there is vast empirical evidence on the ability of the term spread and other economic and financial indicators to predict recessions, most of these are for the developed economies, with the US featuring most prominently. The evidence is limited for emerging economies like South Africa. In general, the probit model dominates the literature on forecasting recession probability. Also much attention has been focused on the aggregate term spread with little or no attention on the predictive power of the different components of the term spread namely the expected term spread and term premium. Aside from Karnizova and Li (2014), there appears to be no other studies that used the economic policy uncertainty index to predict recession probability. The current study fills these gaps and therefore makes a contribution to the literature.

\section{Data and Empirical Models}

The data analysed cover the period between 1990:Q1 and 2012:Q1, with the start and end points being purely driven by data availability of the EPU index. Our measure of long-term and shortterm interest rates are the 10-year government bonds and 3-month Treasury Bill (TB) rates, respectively, obtained from the International Monetary Fund's International Financial Statistics. The term spread is calculated as the difference between the 10-year government bond and 3month TB rate. Data on recession was obtained from SARB. According SARB data, there are 30 downswing quarters and 59 upswing quarters in the sample with three identifiable recessions. The Economic Policy Uncertainty index was sourced from Brogaard and Detzel (2015). ${ }^{1}$ The authors construct the EPU indexes based on data from an internet search and count of articles that use keywords associated with economic policy uncertainty in these countries. The source for their data is the Access World News database. Aside from these individual series, we extracted factors from 177 macroeconomic variables which cover inflation, real activity, asset prices and

\footnotetext{
${ }^{1}$ We thank Jonathan Brogaard for providing us with the EPU data. Note that, though Brogaard and Detzel (2015) created the EPU for 21 countries in an earlier version of the paper, they only concentrated on the US stock market in the published version.
} 
monetary series, as in Gupta (2016). ${ }^{2}$ Incorporating large amount of information helps to avoid the problem of misspecification due to missing information on important fundamentals, thus preventing omitted variable bias. The data on the 177 macroeconomic and financial variables were obtained from different data providers including the SARB, Statistics South Africa, Bureau for Economic Research (BER), South Africa, ABSA Group Limited, South Africa, National Association of Automobile Manufacturers of South Africa, OECD statistics, Oxford Economics, and IMF International Financial Statistics. Note that the factors are extracted recursively over the out-of-sample period based on information at each point of the expanding in-sample period, with the optimal number of factors being chosen by the tests developed by Bai and $\mathrm{Ng}$ (2002). In general, we tend to choose five factors consistent with Gupta (2016).

We start by showing how we decomposed the term spread into term premium and expected spread using the fractional integration approach of Gil-Alana and Moreno (2012). An identity relation exists between the long-term forward rate and the sum of current and expected shortterm rates plus a time-varying term premium (Backus and Wright 2007). This relation is characterised with quarterly data and short-term rates of quarterly maturity as follows:

$$
i_{t}^{n}=\frac{1}{n} E_{t} \sum_{j=0}^{n-1} i_{t+j}+t p_{t, n}
$$

where $i_{t}^{n}$ is the (n-quarters-ahead) 10 -year rate in quarter $t, i_{t+j}$ is the three-months, i.e, 1 -quarter short rate in quarter $\mathrm{t}+\mathrm{j}(\mathrm{j}=0,1, \ldots, n-1)$ and $t p_{t, n}$ is the term premium on a 10 -year bond with respect to the 1-quarter bond in quarter $t$. Therefore, the expectation of the short-term rate is the key element for the identification of the term premium. ${ }^{3}$

The fractional integration framework allows us to determine the order of integration of a given variable without the restriction of having to choose a priori between zero and one. The order of integration could be zero, a fraction of one, or it could even be above one. Therefore, the approach is agnostic with respect to the order of integration of the short-rate. Accordingly, there is no need to pre-test the orders of integration of the variables as this exercise does not often provide conclusive evidence (Gil-Alana and Moreno, 2012). This method allows us to simultaneously and endogenously determine the order of integration of both the short-rate and the long rate. Hence, we estimate an $A \operatorname{RFIMA(1,d,0)}$ model for the short rate, which, if represented in a single equation, yields:

$$
(1-\rho L)(1-L)^{d}\left(i_{t}-\mu\right)=\xi_{t},
$$

where $|\rho|<1, \mathrm{~L}$ is the lag operator, $\xi_{t}$ is assumed to be ani.i.d. $\left(0, \sigma_{\xi}^{2}\right)$ process, and $d$ is the (possibly fractional) order of integration of the short rate. Model (2) includes $I(0)$ and $I(1)$ processes, that is when $d=0$ and $d=1$, respectively, as special cases.

It is well known that an $I(0)$ process is covariance stationary with (potentially) exponentially decaying autocorrelations values, and is hence a short memory process. Contrary, an I(1) process is nonstationary and non mean reverting. Specifically, the effect of a shock is known to persist forever for an $I(1)$ process. Processes with a fractional value of $d, 0<d<1$, can describe the persistent behaviour of many macroeconomic and financial time series in a much more flexible way than the $\mathrm{I}(0)$ and $\mathrm{I}(1)$ cases.For $0<d<0.5, i_{t}$ will be covariance stationary, while $d<1$ implies mean reversion at a slow rate of hyperbolic decay.

\footnotetext{
${ }^{2}$ Further details can be found in the data appendix of Aye et al., (2016).

${ }^{3}$ More details can be found in Gil-Alana and Moreno (2012).
} 
Also, note that we lose 10 years (forty quarters) of data. We start the estimation of decomposition in 1981:1, but the actual sample starts from 1990:1. To forecast recessions, we employ the probit model with our data divided into in-sample (1990:1 to 1999:4) and out-ofsample (2000:1 to 2012:1) in order to capture the inflation targeting period in South Africa. Despite their simplicity, probit models generate recession forecasts that are often comparable and in some cases superior to those of more sophisticated models (Chen, 2009; Karnizova and $\mathrm{Li}, 2014)$.The standard probit model is defined in line with a linear relationship of the form

$$
y_{t+k}^{*}=\alpha+\beta^{\prime} x_{t}+\varepsilon_{t},
$$

where $y_{t+k}^{*}$ is the dependent latent variable, $x_{t}$ is a px1 vector of explanatory variable, and $\varepsilon_{t}$ a normally distributed disturbance term. It is assumed that the observed dependent variable $R_{t}$ is related to $y_{t}^{*}$ as follows:

$$
\left\{\begin{array}{l}
R_{t}=1, \text { if } y_{t}^{*}>0 \\
R_{t}=0, \text { if } y_{t}^{*} \leq 0
\end{array}\right.
$$

The form of the estimated equation is given as:

$$
P\left(R_{t+k}=1 \mid x_{t}\right)=F\left(\alpha+\beta^{\prime} x_{t}\right),
$$

where $R_{t+k}$ is the zero-one recession indicator in period $t+k$, with $k$ denoting the forecast horizon. $F$ is the normal cumulative distribution function for $-\varepsilon$. We estimate the following ten empirical models:

Model 1 = Factors only

Model $2=$ Model $1+$ term spread

Model $3=$ Model $1+$ expected spread

Model $4=$ Model 1 + term premium

Model $5=$ Model 1+expected spread + term premium

Model $6=$ Model 1+EPU

Model $7=$ Model 2+EPU

Model $8=$ Model 3+EPU

Model $9=$ Model4+EPU

Model $10=$ Model5+EPU. ${ }^{4}$

\section{Results}

The fractional integration estimates of the short and long-term interest rates are shown in Table 1 for the full-sample. For the short interest rate, $\mathrm{d}=0.55$ and is significantly different from zero. This implies that the short rate is not covariance stationary, but is still mean-reverting, and hence the effect of shocks on it will die away in the long-run. For the long rate, $d=0.14$, implying that it is a covariance stationary series. However, its autocorrelations and response to a shock will

\footnotetext{
${ }^{4}$ Alternatively, we could have employed model averaging approaches of the above models.
} 
disappear more slowly than that of a standard $(d=0)$ stationary series. ${ }^{5}$ The parameter estimates obtained recursively over the out-of-sample period are, in turn, used to decompose the termspread in a recursive fashion. This ensures that the forecasting exercise does not suffer from a forward-looking bias, with the forecaster having data information only to the point from which forecasts are generated.

Table 1: Short and long-term interest rates: fractional integration estimates.

\begin{tabular}{lllll}
\hline & Short rate & $\begin{array}{l}95 \% \text { Confidence } \\
\text { interval }\end{array}$ & Long rate & $\begin{array}{l}95 \% \text { Confidence } \\
\text { interval }\end{array}$ \\
\hline$d$ & 0.554 & {$[0.112,0.885]$} & 0.143 & {$[-0.371,0.560]$} \\
$\rho$ & 0.767 & {$[0.561,0.868]$} & 0.891 & {$[0.801,0.973]$} \\
$\mu$ & 8.067 & {$[7.717,8.641]$} & 12.711 & {$[12.001,13.414]$} \\
\hline
\end{tabular}

We compute the out-of-sample probabilities of a recession based on the recursive estimation, which takes into account the availability of data. Unlike the in-sample forecast which uses information that was not available at the time of the forecast, the out-of-sample forecast uses only the information available to market participants at the time of the forecast. While our insample period ranges from 1990:Q1 to 1999:Q4, the out-of-sample covers from 2000:Q1 to 2012:Q1.As noted earlier we estimate 10 probit specifications ranging from extracted factors only to a combination of the factors and decomposed term spread and economic policy uncertainty index.

We calculate a forecast error in order to provide a more formal quantitative measure for comparing the predictive ability of the various models. Although the dependent variable is unobservable, the fact that an ideal model should give a probability of one in a recession period and zero in a non-recession period, allows us to calculate the difference between the recession dummy $\left(R_{t}\right)$ and the predicted recession probabilities. For this purpose we use the root mean square error (RMSE). Specifically, we use the relative root mean square error as our evaluation criteria, that is, each model's forecast is evaluated relative to a model without any predictors and involving only a constant, that is, a model with constant only. ${ }^{6}$ Values less than 1 show that the unrestricted model (that is the model with predictors) has a better forecast performance than the restricted model, i.e., the model with just a constant.

The results are presented in Table 2 for the 10 models for 1, 2, 4, 6 and 8 horizons. At horizons one and two, we find that none of the models outperforms the model with constant only since the values are all above 1. However, Model 3 has the least RMSE value at horizons 1 and 2 even though its performance is not better than that of a model with a constant. At horizons 4, 6 and 8 , a number of models performed better than the model with constant only. These are Model 3 at horizons, 4, 6 and 8, Model 5 at horizon 8, Model 8 at horizons 4 and 6, and Model 10 at horizon 8 . Not only is the performance of Model 8 better than that of a constant only model, it also outperforms the other 9 models at horizons 4 and 6, while Model 5 did the same at horizon 8. Therefore, one can conclude that the best forecasting model for South Africa's recession is Model 8 which incorporates the five extracted factors, expected spread and economic policy

\footnotetext{
${ }^{5}$ We also estimated models that were $\mathrm{I}(0)$ and $\mathrm{I}(1)$ (i.e., $\mathrm{d}=0$ and 1 , respectively), and also the ARFIMA model without autocorrelation; but all these models had relatively poor fits when compared to our ARFIMA $(1, \mathrm{~d}, 0)$ model. Complete details of these results are available upon request from the authors.

${ }^{6}$ In the context of probit models, other metrics for evaluating the forecasting performance could be employed such as classic contingency-table tests, the quadratic probability score, the Brier skill score and ROC curves. We believe the results were very similar using these alternative methods.
} 
uncertainty (EPU) index. It is important to note that Model 3, the second best forecasting model is also a model containing the factors and expected spread. This clearly points to the specific role of the expected spread and justifies the need to decompose the term spread into its subcomponents (expected spread and term premium) as this shows which component is driving the forecasting ability of the term spread most. The term premium appears to have limited predictive power for South Africa's recessions. This is because it performs well only in conjunction with expected spread (Model 5) at horizon 8, implying that left alone, term premium has no predictive power for recession. The fact that Model 8 performs better than Model 3 provides evidence of the supporting role of EPU since Model 8 nests Model 3 with the difference being the inclusion of EPU in Model 8. We also observe that across all models and horizons, the smallest RMSE is obtained at horizon 4, implying that the best forecast for recessions occurs at four quarters ahead.

Subsequently, we provide an in-sample (full sample) recession probability predictions using the best model and the entire data. The results are presented in Figure 1.Figure 1 shows that model 8 was able to predict accurately all the three turning points in our sample. About $80 \%$ to $90 \%$ forecast accuracy was observed for the first and third recession periods at least up to six quarters ahead, whereas only about 30\% to 60\% accuracy was observed beyond this. For the second recession period, the prediction accuracy ranges between $60 \%$ to $70 \%$ at all horizons except the seventh and eight horizons where the accuracy is about $50 \%$. We also observe that aside from the second recession period in our sample, where the models had basically similar predictions at all the horizons, the best prediction occurred at four quarters ahead. This confirms the out-ofsample results. This finding seems to contradict most of the previous studies in South Africa with best prediction at two quarters ahead. This may not be surprising given that incorporating the different components of the term spread and economic policy uncertainty index has improved the prediction models. This feature thus distinguishes the current study from the previous South African studies. However, in support of previous South African studies, we also observe a false prediction of recession between 2002 and 2003 although with a lower probability.

Table 2: Out-of-sample relative RMSEs: 2000:Q1 to 2012:Q1

\begin{tabular}{llllll}
\hline & $\mathrm{h}=1$ & $\mathrm{~h}=2$ & $\mathrm{~h}=4$ & $\mathrm{~h}=6$ & $\mathrm{~h}=8$ \\
\hline Model 1 & 1.223 & 1.146 & 1.141 & 1.032 & 1.015 \\
Model 2 & 1.229 & 1.172 & 1.268 & 1.243 & 1.117 \\
Model 3 & 1.183 & 1.100 & 0.767 & 0.913 & 0.914 \\
Model 4 & 1.286 & 1.223 & 1.360 & 1.317 & 1.096 \\
Model 5 & 1.256 & 1.179 & 1.014 & 1.153 & $\mathbf{0 . 8 6 4}$ \\
Model 6 & 1.386 & 1.266 & 1.302 & 1.304 & 1.243 \\
Model 7 & 1.215 & 1.112 & 1.151 & 1.180 & 1.131 \\
Model 8 & 1.343 & 1.187 & $\mathbf{0 . 7 4 8}$ & $\mathbf{0 . 8 3 3}$ & 0.953 \\
Model 9 & 1.311 & 1.213 & 1.297 & 1.334 & 1.238 \\
Model 10 & 1.231 & 1.140 & 1.282 & 1.128 & 0.929 \\
\hline
\end{tabular}

Note: Figures in bold indicate best forecasting models for each horizon h, relative to a benchmark model with only constant. 

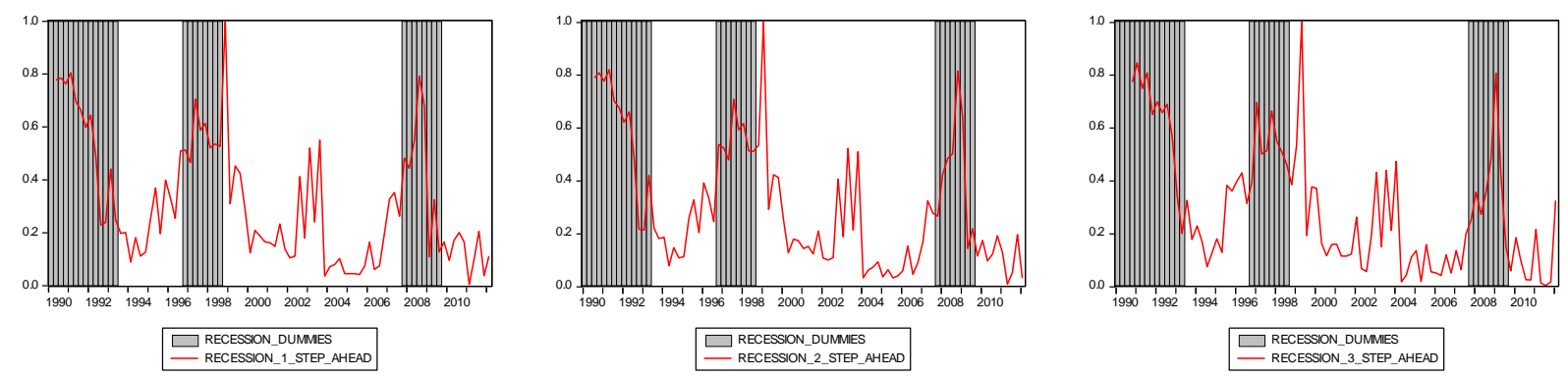

$\square$ RECESSION_DUMMES $\square$ RECESSON_DUMMES
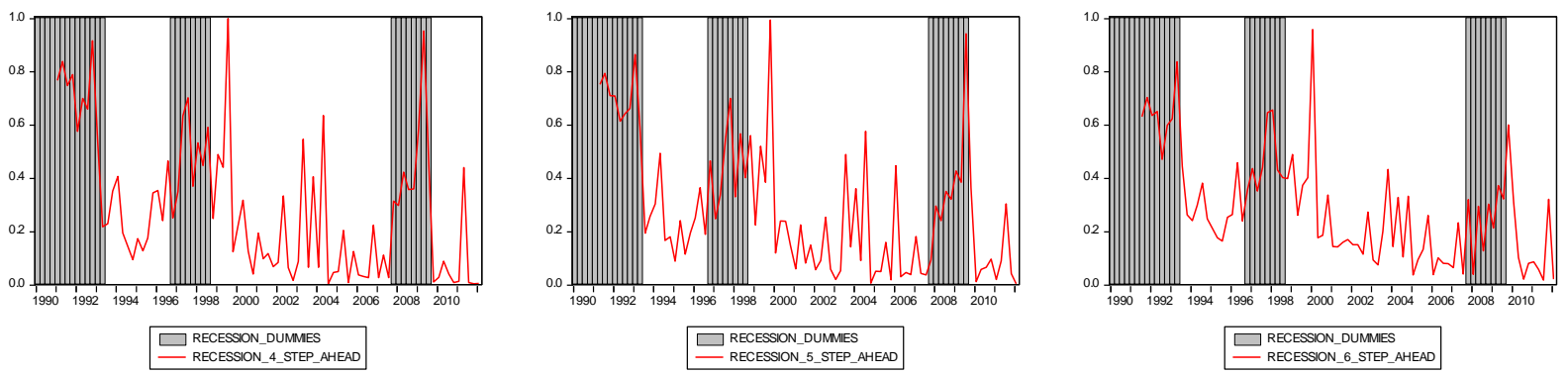

$\square$ RECESSION_DUMMMES

$\square$ RECESSSON_DUMMES
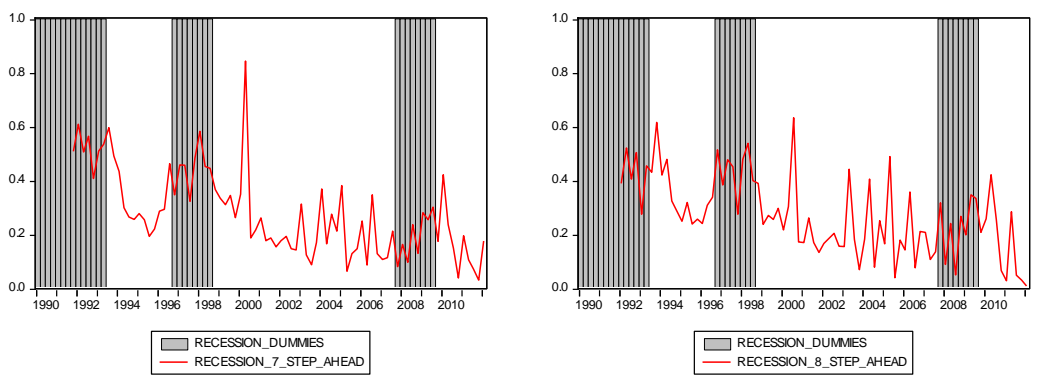

Figure 1: Full sample predicted recession probabilities with gray shaded SARB recession dates: 1990:Q1 to 2012:Q1.

As a robustness check to determine whether the decomposition of the term spread into expected spread and term premium is useful, we used a longer sample to avoid any possible sample length bias. ${ }^{7}$ The data consist of the term spread, the expected spread, the term premium and real stock returns which were sourced from the Global Financial Database. The stock returns were included since they are also good predictors of recession. Again we divided the data into insample (1946:1 to 1999:4) and out-of-sample (2000:1 to 2017:4) in order to capture the inflation targeting period in South Africa. For this analysis, four separate recession forecasting probit models were estimated and compared with a model without predictors (random walk model). These are given as:

Model 1: Term spread + Real stock returns

Model 2: Expected spread + Real stock returns

Model 3: Term premium + Real stock returns

Model 4: Expected spread + Term premium + Real stock returns

\footnotetext{
${ }^{7}$ The factors and EPU are excluded from this robustness analysis given that these limit us to a shorter length sample.
} 
The relative RMSE are presented in Table 3. Clearly, the model with only expected premium augmented with stock returns outperformed the rest models. This is followed by the model with expected spread and term premium augmented with stock returns. While these two models outperformed the random walk model at all horizons, the model with only either the term spread or term premium forecast worse than the random walk model. These findings are consistent with our benchmark analysis in that the role of the expected spread is clearly observed thus justifying the decomposition approach followed in this paper. Again unlike previous South Africa's studies that obtained the best forecast at horizon two, the analysis here shows the best forecast is at a longer horizon, specifically horizon 5 . Therefore, using model 2 , we produce the full sample predicted recession probabilities. Figure 2 shows that model 2 is able to predict most of the turning points with high accuracy especially from the 1980s. For about three turning points, a near $100 \%$ prediction accuracy is observed.

Table 3: Out-of-sample Relative RMSEs: 2000Q1 to 2017Q4

\begin{tabular}{lllllllll}
\hline & $\mathrm{h}=1$ & $\mathrm{~h}=2$ & $\mathrm{~h}=3$ & $\mathrm{~h}=4$ & $\mathrm{~h}=5$ & $\mathrm{~h}=6$ & $\mathrm{~h}=7$ & $\mathrm{~h}=8$ \\
Model 1 & 1.035 & 1.034 & 1.033 & 1.030 & 1.030 & 1.031 & 1.031 & 1.028 \\
Model 2 & $\mathbf{0 . 9 2 5}$ & $\mathbf{0 . 9 2 4}$ & $\mathbf{0 . 9 2 5}$ & $\mathbf{0 . 9 2 5}$ & $\mathbf{0 . 9 2 3}$ & $\mathbf{0 . 9 2 5}$ & $\mathbf{0 . 9 2 6}$ & $\mathbf{0 . 9 2 6}$ \\
Model 3 & 1.042 & 1.041 & 1.040 & 1.037 & 1.034 & 1.037 & 1.035 & 1.032 \\
Model 4 & $\mathbf{0 . 9 9 1}$ & $\mathbf{0 . 9 9 0}$ & $\mathbf{0 . 9 8 9}$ & $\mathbf{0 . 9 8 7}$ & $\mathbf{0 . 9 8 6}$ & $\mathbf{0 . 9 8 9}$ & $\mathbf{0 . 9 9 0}$ & $\mathbf{0 . 9 8 8}$ \\
\hline
\end{tabular}

Note: Figures in bold indicate best forecasting models for each horizon h, relative to a benchmark model with only constant.

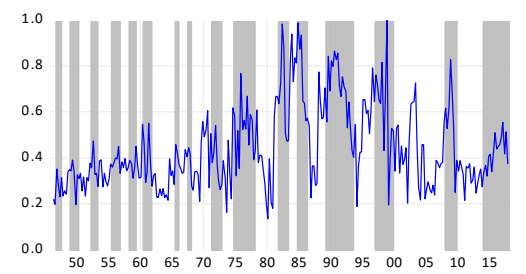

$\square$ RECESION_DUMMIES — RECESSION_F_H1

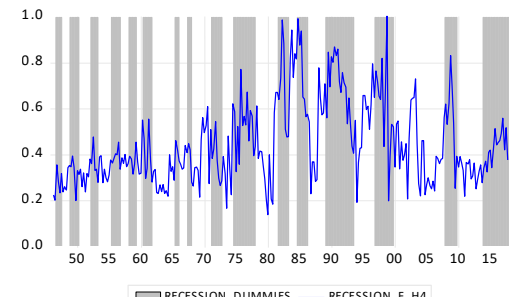

$\square$ RECESSION_DUMMIES — RECESSION_F_H4

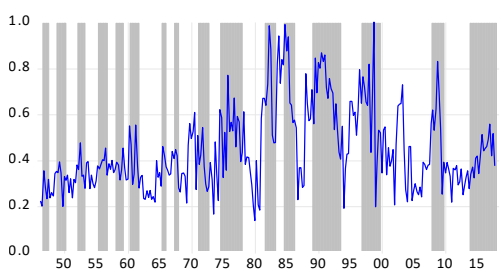

$\square^{\text {RECESION_DUMMIES — RECESION_F_H? }}$

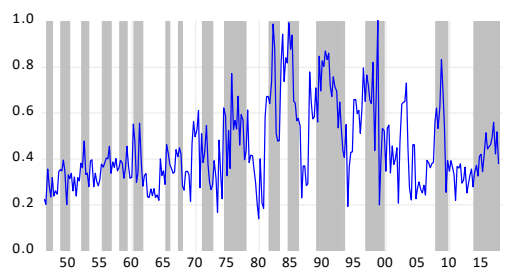

$\square$ RECESION_DUMMMES —RECESION_F_H2

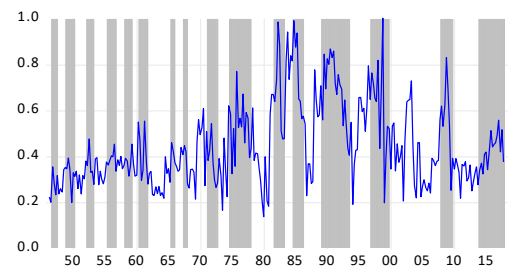

$\square$ RECESION_DUMMIES — RECESSION_F_HS

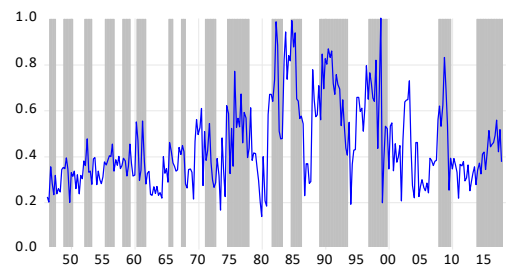

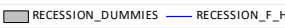

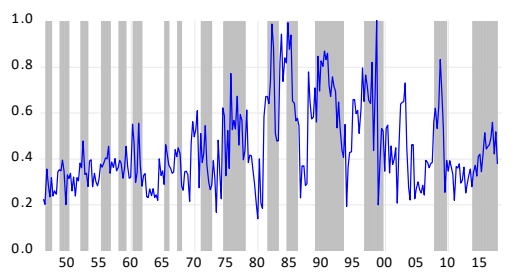

$\square$ RECESION_DUMMIES — RECESION_F_H3

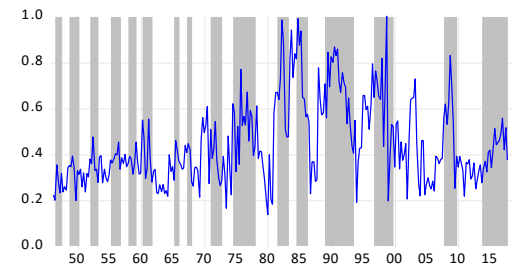

$\square$ RECESIION_DUMMIES - RECESION_F_H6

Figure 2: Full sample predicted recession probabilities with gray shaded SARB recession dates: 1946:Q1 to 2017:Q4. 


\section{Conclusions}

This study investigates the forecasting ability of the decomposed term spread -expected spread and term premium- and economic policy uncertainty index for recessions in South Africa. Using quarterly data spanning 1990:Q1 to 2012:Q1 and 10 specifications of the probit model, we show that all our models are able to predict the three recession periods in our sample. The best out-ofsample forecasting model is the one that incorporates the expectation component and economic policy uncertainty. Using this model, we provide evidence based on the full sample probability that the best forecast for South Africa's recession is at the four quarters ahead horizon. This is an improvement over the previous studies in South Africa which found the best forecast at two quarters ahead. This improvement may be attributed to the new variables included in the analysis. Therefore, our findings suggest that economic forecasters as well as monetary and fiscal policy authorities would gain from monitoring not only the aggregate yield curve but also the components, especially the expected term spread as well as the economic policy uncertainty index. A robustness analysis with a longer sample (1946q1 to 2017q4) though without the factors and economic policy uncertainty still validated the usefulness of decomposing the term spread. The need for more credible policy cannot be overstressed as increased uncertainty about monetary and fiscal policies for instance may delay investment and employment decisions, which may lead to prolonged downturn and hence recessions in the economy. As a final comment, and given the results by Ryberg (2010) in that the ability of dynamic probit models in forecasting recessions, more accurate results may be obtained using a dynamic probit structure rather than the static one used in the work. This is something that we will be examined in future papers.

\section{References}

Ang, A., Piazzesi, M. and Wei,M. (2006). What does the yield curve tell us about GDP growth? Journal of Econometrics, 131(1-2), 359-403.

Aye, G. C., Balcilar, M., and Gupta, R. (2016). The Effectiveness of Monetary Policy in South Africa under Inflation Targeting: Evidence from a Time-Varying Factor-Augmented Vector Autoregressive Model. University of Pretoria, Department of Economics, Working Paper No. 201653.

Backus, D.K. and Wright, J.H. ( 2007). Cracking the conundrum. Brooking Papers on Economic Activity 1, 293-316.

Bai, J., and Ng, S. (2002). Determining the number of factors in approximate factor models. Econometrica, 70 (1), 191-221.

Baker, S., Bloom, N., Davis, S., 2016. Measuring economic policy uncertainty. Quarterly Journal of Economics 131, 4, forthcoming, doi: 10.1093/qje/qjw024.

Born, B. and Pfeifer, J. (2014).Policy risk and the business cycle. Journal of Monetary Economics 68, 68-85. 
Botha, F. and Keeton, G. (2014).A note on the (continued) ability of the yield curve to forecast economic downturns in South Africa. South African Journal of Economics 82, 3, 468-473.

Brogaard, J., and Detzel. A. (2015). The asset pricing implications of government economic policy uncertainty. Management Science, 61(1), 3-18.

Chatterjee, U.K. (2016). Do stock market trading activities forecast recessions? Economic Modelling, 59370-386.

Chatterjee, U.K. (2018). Bank Liquidity Creation and Recessions. Journal of Banking and Finance 90, 64-75.

Chauvet, M. and Potter, S. (2005). Forecasting recessions using the yield curve. Journal of Forecasting, 24(2), 77-103.

Chauvet, M. and Senyuz, Z. (2016). A dynamic factor model of the yield curve components as a predictor of the economy. International Journal of Forecasting 32, 324-343.

Chen, S.S. (2009), Predicting the bear market: macroeconomic variables as leading indicators, Journal of Banking and Finance 33, 211-223.

Chinn, M. and Kucko (2015) The Predictive Power of the Yield Curve Across Countries and Time. International Finance,18 (2), 129-156.

Chionis, D., Gogas, P. and Pragidis, I. (2010). Predicting European Union recessions in the euro era: the yield curve as a forecasting tool of economic activity. International Advances in Economic Research, 16, 1-10.

Clay, R. and Keeton, G. (2011). The South African yield curve as a predictor of economic downturns: An update. African Review of Economics and Finance, 2(2), 167-193.

Dombrosky, A. M. and Haubrich, J. G. (1996).Predicting real growth using the yield curve. Economic Review Journal, 32: 26-35.

Döpke, J., Fritsche, U. and Pierdzioch, C. (2017).Predicting recessions with boosted regression trees. International Journal of Forecasting, 33, 745-759.

Duarte, A., Venetis, I.A. and Paya, I. (2005). Predicting real growth and the probability of recession in the Euro area using the yield spread. International Journal of Forecasting, 21, 2261277.

Erdogan, O., Bennett, P. and Ozyildirim, C. (2015).Recession prediction using yield curve and stock market liquidity deviation measures. Review of Finance, 19, 407-422

Ergungor, O.E. (2016) Recession Probabilities. Federal Reserve Bank of Cleveland, Economic Commentary, Number 2016-09.

Estrella, A. and Mishkin, F. S. (1996): The yield curve as a predictor of U.S. recessions. Current Issues in Economics and Finance, 2(7), 1-6.

Estrella, A. and Mishkin, F.S. (1997). The predictive power of the term structure of interest rates in Europe and the United States: Implications for the European Central Bank. European Economic Review, 41(7), 1375-1401. 
Estrella, A. and Mishkin, F.(1998).Predicting US recessions: financial variables as leading indicators. Rev. Econ. Stat. 80 (1), 45-61.

Estrella, A., Rodrigues, A. R.and Schich, S. (2003). How stable is the predictive power of the yield curve? Evidence from Germany and the United States. The Review of Economics and Statistics, 85(3), 629-644.

Fernández-Villaverde, J., Guerrón-Quintana, P., Kuester, K. and Rubio-Ramírez, J., (2015). Fiscal volatility shocks and economic activity. American Economic Review, 105(11), 3352-3384.

Galvaõ, A.B.C. (2006). Structural break threshold VARS for predicting us recessions using the spread. Journal of Applied Econometrics, 21, 463-487.

Gil-Alana, L.A. and Moreno, A. (2012).Uncovering the US term premium: An alternative route. Journal of Banking and Finance, 36, 1181-1193.

Guérin, P. and Leiva-Leon, D. (2017) Model averaging in Markov-switching models: Predicting national recessions with regional data. Economics Letters 157, 45-49.

Gupta, R., Hollander, H. and Steinbach, R. (2015) Forecasting Output Growth using a DSGEBased Decomposition of the South African Yield Curve. University of Pretoria, Department of Economics, Working Paper, No. 201567.

Gupta, R. (2016). Forecasting inflation in an inflation targeting economy: structural versus nonstructural models. Applied Economics, http://dx.doi.org/10.1080/00036846.2016.1237760.

Hamilton, J. and Kim, D., (2002). A re-examination of the predictability of the yield spread for real economic activity. Journal of Money, Credit and Banking 34 (2), 340-360.

Hasegawa, M. and Fukuta, Y. (2011). An empirical analysis of information in the yield spread on future recessions in Japan. Applied Economics, 43, 151865-1881.

Karnizova, L. and Li, J.C. (2014) Economic policy uncertainty, financial markets and probability of US recessions. Economics Letters 125, 261-265

Karunaratne, N.D. (2002). Predicting Australian growth and recession via the yield curve, Economic Analysis and Policy 32, 2, 233-250.

Kessel, R. (1965). The cyclical behavior of the term structure of interest rates. National Bureau of Economic Research Occasional Papers 91.

Kim, D. H. and Wright, J. H. (2005). An arbitrage-free three-factor term structure model and the recent behavior of long-term yields and distant-horizon forward rates. Board of Governors of the Federal Reserve System Finance and Economics Discussion Series, No. 2005-33, August.

Khomo, M.M. and Aziakpono, M.M. (2007). Forecasting recessions in South Africa: A comparison of the yield curve and other economic indicators. South African Journal of Economics, 75(2), 194-212.

Moersch, M. and Pohl, A. (2011). Predicting recessions with the term spread - recent evidence from seven countries. Applied Economics Letters, 18, 131285-1288.

Mohapi, T. and Botha, I. (2013).The explanatory power of the yield curve in predicting recessions in South Africa. International Business and Economics Research Journal, 12 (6), 613634. 
Moneta, F. (2005). Does the yield spread predict recessions in the Euro Area? International Finance, 8, 2263-301.

Moolman, E. (2002). The Term Structure as a Predictor of Recessions. Journal for Studies in Economics and Econometrics, 26(6), 43-51.

Moore, G.H. (1967). What is a Recession? The American Statistician, 21(4), 16-19.

Ng, E.C.Y.. (2012). Forecasting US recessions with various risk factors and dynamic probit models. Journal of Macroeconomics, 34,1112-125.

Nyberg, Henri (2010) Dynamic probit models and financial variables in recession forecasting. Journal of Forecasting 29, 215-230.

Nyberg, H. (2014).A bivariate autoregressive probit model: business cycle linkages and transmission of recession probabilities. Macroeconomic Dynamics, 18,838-862.

Pauwels, L. and Vasnev, A. (2014). Forecast combination for U.S. recessions with real-time data. The North American Journal of Economics and Finance, 28138-148.

Proaño, C.R. and Theobald, T. (2014).Predicting recessions with a composite real-time dynamic probit model. International Journal of Forecasting, 30, 4898-917.

Ratcliff, R. (2013). The "probability of recession": Evaluating probabilistic and non-probabilistic forecasts from probit models of U.S. recessions. Economics Letters, 121, 2311-315.

Rosenberg, J.V. and Maurer, S. (2008).Signal or Noise? Implications of the term premium for recession forecasting, FRBNY Economic Policy Review, 14(1), 1-11. 